\title{
Trauma-induced dual vascular lesions in the liver- hepatic pseudoaneurysm with arteriohepatic venous fistula
}

\author{
Lakshmikanth Halegubbi Karegowda, ${ }^{1}$ Tadigadapa Keerthi, ${ }^{1}$ Taruna Rathore, ${ }^{2}$ \\ Kadavigere Rajagopal ${ }^{1}$
}

${ }^{1}$ Radiodiagnosis, Manipal Academy of Higher Education, Kasturba Medical College Manipal, Manipal, India Undergraduate, Manipal Academy of Higher Education, Kasturba Medical College Manipal, Manipal, India

\section{Correspondence to}

Professor Kadavigere Rajagopal, rajagopalkv@yahoo.com

Accepted 20 July 2018

\section{DESCRIPTION}

A 17-year-old boy presented to the emergency triage with severe abdominal pain following blunt abdominal trauma. The patient was conscious, hypotensive with blood pressure $60 / 30 \mathrm{~mm} \mathrm{Hg}$, pulse rate 110/min and per abdomen examination revealed abdominal distension, tenderness, rigidity and free fluid. FAST (Focused Assessment with Sonography in Trauma) imaging revealed liver lacerations and haemoperitoneum. The patient was initially stabilised with inotropes, intravenous fluids and adequate analgesics and had to be directly taken up for emergency laparotomy as the ideal protocol of performing an emergency CT was forgone due to technical issues with the CT machine. Laparotomy revealed grade $\mathrm{V}$ liver injury with active bleeding and haemoperitoneum of about 2 L. Haemostatic agent (AbGel) and multiple intra-abdominal packs were used to stop bleeding, and massive blood transfusion protocol was activated. The patient was transferred to intensive care unit where he improved with conservative treatment. Before removing the intra-abdominal packs by relaparotomy, a contrast CT study was performed. Apart from showing grade V liver injury, the CT showed a large lobulated outpouching arising from a segmental branch of the right hepatic artery and communicating

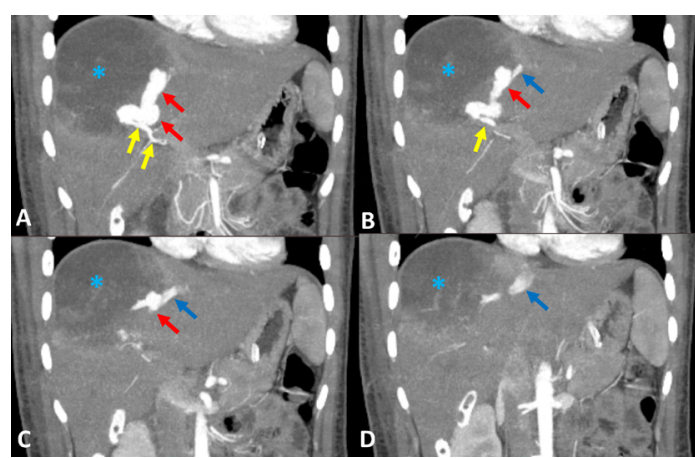

Figure 1 Sequential post-contrast coronal CT images, maximum intensity projection of arterial phase from anterior to posterior direction (A to D). Shows a large lobulated contrast-filled outpouching (red arrows) arising from the segmental branch of right hepatic artery (yellow arrows) located at the bed of a large hypodense haematoma (blue asterisk) and communicating with the middle hepatic vein (blue arrows) suggestive of hepatic artery pseudoaneurysm with arteriohepatic venous fistula.

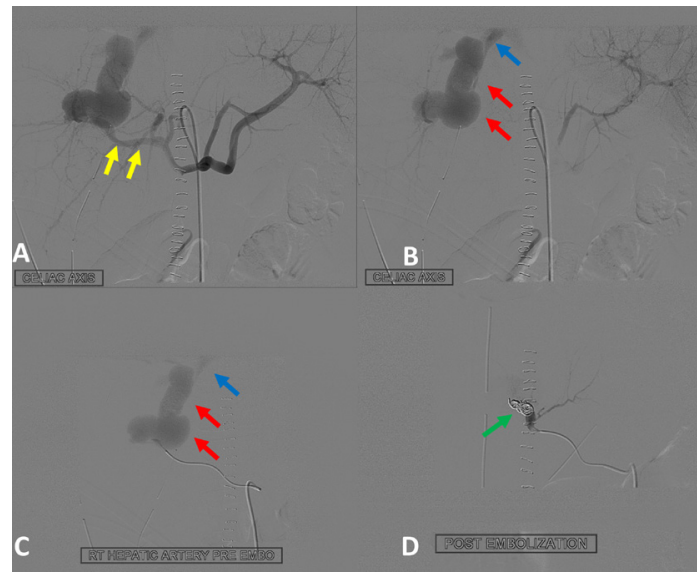

Figure 2 Coeliac artery ( $\mathrm{A}$ and $\mathrm{B}$ ) and selective right hepatic artery $(C)$ angiograms showing the segmental branch of right hepatic artery (yellow arrows) opening into the pseudoaneurysm (red arrows) and fistulising into the middle hepatic vein (blue arrows) confirming the CT diagnosis. Image $D$ is post-coil embolisation angiogram showing multiple small coils deployed at the neck of the pseudoaneurysm (green arrow) with no opacification of the vascular lesions suggestive of complete occlusion.

with the middle hepatic vein suggestive of hepatic artery pseudoaneurysm with arteriohepatic venous fistula (figure 1). Following contrast-enhanced CT findings, endovascular embolisation of the vascular lesions using multiple small coils was performed, which led to their complete closure (figure 2). The patient fully improved after 10 days of hospital stay and was discharged.

Hepatic vascular injuries are known to occur commonly after a penetrating injury, and the incidence of these lesions following blunt trauma is unknown. Though hepatic artery pseudoaneurysm is frequently seen due to traumatic, inflammatory or neoplastic causes, the occurrence of arteriohepatic venous fistula is rare with the present case being the third case reported in the context of blunt trauma. ${ }^{12}$

The fistulous vascular communication or shunts within the liver are divided into arteriovenous and venovenous types. Arteriovenous type is further divided into arterioportal and arteriohepatic subtypes. Among the subtypes, the arterioportal fistulae are commonly encountered following trauma, neoplasm or iatrogenic injury. It is common due to the close proximity of the 
hepatic artery to portal vein within the liver. The occurrence of the arteriohepatic venous fistula, on the other hand, is rare as there is larger distance between the hepatic vein and the artery. $^{2}$

Contrast CT abdomen, especially the arterial phase of imaging (CT angiography) plays a vital role in confidently diagnosing the condition. This is due to its multiplanar reformation, maximum intensity projection and $3 \mathrm{D}$ volume rendering capabilities, which aid in enhanced visualisation of the lesions. Conventional angiography is useful for both confirming and treating the lesions. Early intervention through endovascular approach reduces the chances of hepatic surgery and number of blood transfusions. The practical strategy for therapeutic management of these lesions was laid by Dessouky et al..$^{3}$ Accordingly, they are divided

\section{Learning points}

- Hepatic vascular injuries are known to occur commonly after a penetrating injury, and the incidence of these lesions following blunt trauma is unknown.

- An intrahepatic arterioportal fistula is common due to close proximity of the hepatic artery to portal vein whereas the arteriohepatic venous fistula is rare as there is larger distance between the hepatic vein and the artery.

- Contrast CT abdomen plays a vital role in confidently diagnosing the condition due to its various post-processing capabilities, which aid in enhanced visualisation of the lesions. Conventional angiography is useful for both confirming and treating the lesions. into three groups. Group I includes asymptomatic patients with small shunts of 3-6 mm managed with conservative treatment, group II are symptomatic patients with large shunts of more than $15 \mathrm{~mm}$ managed with endovascular intervention while group III are patients with diffuse shunts needing surgical treatment. ${ }^{23}$ Our case belonged to group II category of lesions and hence was treated by endovascular intervention.

Contributors LHK was involved in designing, drafting the work and final approval of the version to be published. TK was involved in conception, drafting the work and final approval of the version to be published. TR was involved in the acquisition, revising the work critically for important intellectual content and final approval of the version to be published. KR was involved in the analysis of data, drafting the work and final approval of the version to be published. All the authors agree to be accountable for all aspects of the work in ensuring that questions related to the accuracy or integrity of any part of the work are appropriately investigated and resolved.

Funding The authors have not declared a specific grant for this research from any funding agency in the public, commercial or not-for-profit sectors.

Competing interests None declared.

Patient consent Obtained.

Provenance and peer review Not commissioned; externally peer reviewed.

\section{REFERENCES}

1 Hung S-C, Chen J-D, Tiu C-M, et al. Traumatic hepatic pseudoaneurysm with arterio-hepatic venous fistula: diagnosis with MDCT angiography. Injury Extra 2006;37:349-52.

2 Chandrasekharan R, KP S, Moorthy S, et al. Traumatic hepatic arteriohepatic venous fistula managed with selective coil embolization: a case report. $B J R \mid$ case reports 2017;3:20150512.

3 Dessouky BAM, El Abd OL, Abdel Aal ESM. Intrahepatic vascular shunts: strategy for early diagnosis, evaluation and management. The Egyptian Journal of Radiology and Nuclear Medicine 2011;42:19-34.

Copyright 2018 BMJ Publishing Group. All rights reserved. For permission to reuse any of this content visit

http://group.bmj.com/group/rights-licensing/permissions.

BMJ Case Report Fellows may re-use this article for personal use and teaching without any further permission.

Become a Fellow of BMJ Case Reports today and you can:

- Submit as many cases as you like

- Enjoy fast sympathetic peer review and rapid publication of accepted articles

- Access all the published articles

- Re-use any of the published material for personal use and teaching without further permission

For information on Institutional Fellowships contact consortiasales@bmjgroup.com

Visit casereports.bmj.com for more articles like this and to become a Fellow 